\title{
European versus United States Pharmacopeia Disintegration Testing Methods for Enteric-Coated Soft Gelatin Capsules
}

\author{
J. Al-Gousous and P. Langguth* \\ Institute of Pharmacy and Biochemistry, Johannes Gutenberg University, Mainz, Germany
}

e-mail: langguth@uni-mainz.de

\section{ABSTRACT}

The aim of this work was to investigate the differences between the disintegration testing methods specified by the United States Pharmacopeia (USP) and the European Pharmacopoeia (Ph. Eur.) for enteric-coated soft gelatin capsules. Disintegration of the coated capsules in the $\mathrm{pH} 6.8$ buffer stage of the test was much faster under the conditions specified by Ph. Eur. than under the conditions specified by the USP. Further investigation showed that the differences are related to the different buffer capacities and the ionic strengths of the media specified by the two pharmacopeias. This shows the importance of harmonizing such tests among the different pharmacopeias and accounting for factors like buffer capacity and ionic strength when designing appropriate media for disintegration and dissolution tests.

KEYWORDS: Enteric-coated soft gelatin capsules; dissolution; disintegration.

\section{INTRODUCTION}

nteric coatings have been used for decades to delay drug release from oral solid dosage forms until after gastric emptying either to protect the active ingredient from degradation by gastric acid or to protect the gastric mucosa from irritation caused by the active ingredient. These coatings are based on $\mathrm{pH}$-sensitive film-formers that should prevent release under the acidic conditions in the stomach but allow it under the higher $\mathrm{pH}$ conditions in the small intestine. Therefore, for disintegration and dissolution testing, a two-stage testing approach was adopted by the different pharmacopeias for such products: a first stage done in an acidic medium where the coat should prevent disintegration and drug release, and a second stage in a higher $\mathrm{pH}$ buffer where the dosage form should disintegrate $(1,2)$.

However, that the employed testing conditions accurately simulate gastrointestinal (GI) conditions is questionable. For example, a study performed by Wagner et al. (3) more than 40 years ago provided an example where aminosalicylic acid enteric-coated tablets passed the USP disintegration test but failed to release the drug in vivo. In addition, in a study by Wilding et al. (4), enteric-coated naproxen tablets took much longer to disintegrate after gastric emptying in vivo than in the buffer stage of the BP 1988 disintegration test. Another study by Cole et al. (5) showed that the onset of release from enteric-coated HPMC capsules was appreciably earlier during the $\mathrm{pH}$ 6.8 buffer stage of in vitro dissolution testing than after gastric emptying in vivo.
For disintegration testing in particular, the picture isfurther complicated by the fact that different pharmacopeias specify different test conditions for enteric-coated products. Table 1 summarizes the differences between the disintegration testing conditions specified for entericcoated soft gelatin capsules by Ph. Eur. and the USP. In this work, we studied the differences in the test results of the methods when performed on enteric-coated soft gelatin capsules manufactured in-house. The exact causes behind these differences were also investigated.

Table 1. Differences Between the Disintegration Testing Methods for Enteric-Coated Soft Gelatin Capsules According to Ph. Eur. and USP.

\begin{tabular}{|l|c|c|c|}
\hline \multicolumn{1}{|l|}{ Characteristic } & Ph. Eur. & USP \\
\hline \multicolumn{1}{|l|}{ Acid Stage Medium } & $0.1 \mathrm{M} \mathrm{HCl}$ & $\begin{array}{c}0.084 \mathrm{M} \mathrm{HCl} \\
0.034 \mathrm{M} \mathrm{NaCl} \\
0.32 \% \mathrm{w} / \mathrm{v} \mathrm{pepsin}\end{array}$ \\
\hline Acid Stage Duration & $2 \mathrm{~h}$ & $1 \mathrm{~h}$ \\
\hline & $\begin{array}{c}\text { Buffer-Forming } \\
\text { Species } \\
\text { (i.e., phosphate) } \\
\text { Total Conc. (M) }\end{array}$ & 0.154 & 0.05 \\
\cline { 2 - 4 } $\begin{array}{l}\text { pH 6.8 Buffer- } \\
\text { Stage Medium }\end{array}$ & Ionic Strength (M) & 0.463 & 0.094 \\
\cline { 2 - 4 } & Counterions & $\begin{array}{c}\mathrm{Na}^{+} \\
\mathrm{K}^{+}(0.05 \mathrm{M}) \\
\mathrm{Na}^{+}(0.022 \mathrm{M})\end{array}$ \\
\cline { 2 - 4 } & Other Differences & $\begin{array}{c}\text { Inclusion } \\
\text { of enzymes } \\
\text { not } \\
\text { mandatory }\end{array}$ & $\begin{array}{c}\text { Inclusion } \\
\text { of enzymes } \\
\text { mandatory }\end{array}$ \\
\hline
\end{tabular}




\section{MATERIALS AND METHODS \\ Materials}

Uncoated size 4 oval placebo soft gelatin capsules were received as a gift from Catalent Pharma Solutions (Eberbach, Germany). Shellac aqueous solution (Aqualacca 25) was received as a gift from Chemacon (Bühl, Germany). HPMC (Pharmacoat 606) was received as a gift from HARKE (Mülheim an der Ruhr, Germany). All the other materials used were of analytical grade.

\section{Coating of Soft Gelatin Capsules}

Batches of soft gelatin capsules were coated to levels of 12,15 , and $18 \mathrm{mg}$ solid $/ \mathrm{cm}^{2}$ with a coating formulation composed of shellac, HPMC, and glycerin (62.5:25.0:12.5 $\mathrm{w} / \mathrm{w} / \mathrm{w}$ ) dissolved in water at a total concentration of $14.75 \%$ w/w coating solids. A Glatt GC-300 drum coater (Glatt, Germany) was used. The coating parameters were as follows: $900 \mathrm{~g}$ uncoated capsules batch weight; inlet and exhaust air preheated at $30{ }^{\circ} \mathrm{C}$ for $30 \mathrm{~min}$; coating solution input rate of $5 \mathrm{~g} / \mathrm{min}$; air flow rate of 100 $\mathrm{m}^{3} / \mathrm{h}$; coating inlet air temperature of $35^{\circ} \mathrm{C}$; exhaust air temperature of $30^{\circ} \mathrm{C}$; atomizing air pressure of 1.2 bar; and a rotational drum speed of $20 \mathrm{rpm}$.

\section{Disintegration Testing}

All batches were tested using both the USP and Ph. Eur. conditions. In addition, a series of disintegration tests was performed on the $15-\mathrm{mg} / \mathrm{cm}^{2}$ batch, where in each test, some parameter of the USP test was changed to what is specified by Ph. Eur. In one test, it was the duration of the acid stage; in the second test, it was the absence of enzymes; in the third test, it was the ionic strength (adjusted using sodium and potassium chloride to maintain the potassium-sodium ratio) of the buffer; and in the fourth, it was both the total phosphate concentration (reflecting the buffer capacity) and the ionic strength of the buffer.

\section{RESULTS}

All the tested capsules withstood the acid stages. As for the buffer stages, large differences among the disintegration times obtained with the two methods were found as shown in Figure 1. The disintegration times were consistently longer in the USP medium than in the Ph. Eur. medium. These differences were large to the extent that all the three batches passed the Ph. Eur. test but failed the USP test.

An investigation of the causes behind these differences showed that the duration of the acid stage had only a small effect and the enzymes had almost no effect, but ionic strength and buffer capacity had large effects and were the major factors in play (Figure 2).

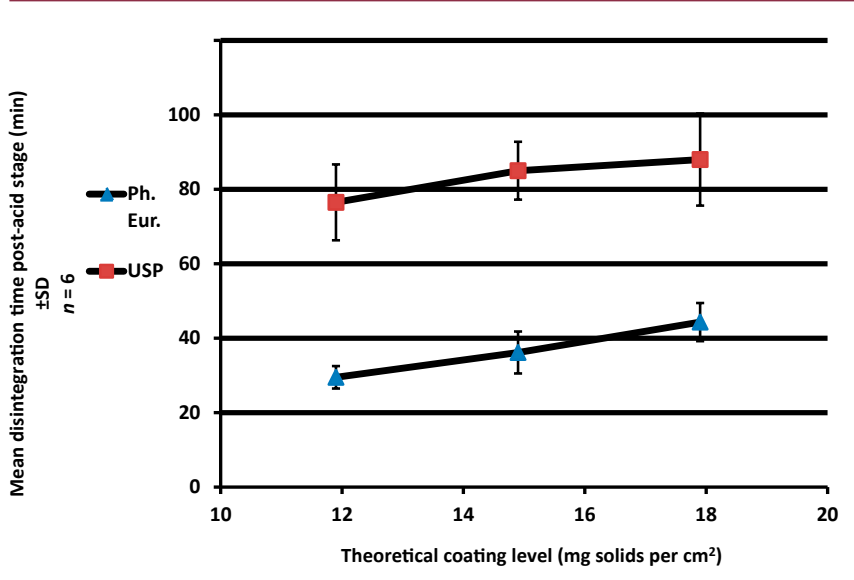

Figure 1. Differences in disintegration times between Ph. Eur. and USP methods.

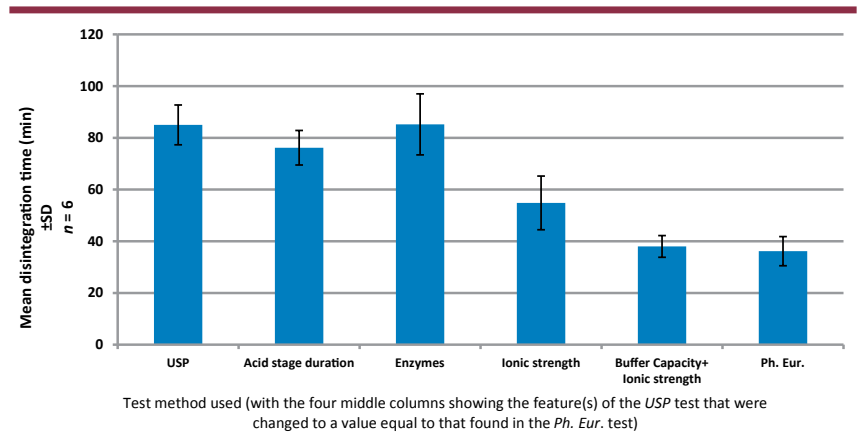

Figure 2. Investigations leading to the causes underlying the different disintegration times of enteric-coated soft gelatin capsules.

\section{DISCUSSION}

The buffer specified by Ph. Eur. for disintegration testing of enteric-coated products promotes faster disintegration than that specified by the USP. The differences in the results between the two methods were related to the different phosphate concentrations (and therefore buffer capacities) and ionic strengths of the two media. The higher buffer capacity of the Ph. Eur. medium (due to its higher phosphate molarity) results in a higher $\mathrm{pH}$ in the immediate vicinity of the shellac molecules within the coat. The acidic shellac molecules cause the $\mathrm{pH}$ within the coat to be lower than the bulk $\mathrm{pH}$, and in a higher buffer capacity medium, this difference will be smaller, which will allow a greater degree of shellac ionization. In addition, the higher ionic strength of the Ph. Eur. medium will shift the mass balance between ionized and un-ionized shellac in the ionization-promoting direction because higher ionic strength will reduce the values of the activity coefficients of ionized shellac molecules. This will lead to further ionization of shellac to compensate the effect of 
reduced activity coefficients on the activity values and maintain chemical equilibrium. These findings are in line with the findings of other groups (7-9) concerning the effects of changing buffer composition on the dissolution characteristics of enteric-coated tablets and pellets. For other enteric-coated products, the testing conditions for tablets are the same as those for capsules in Ph. Eur. In the USP, they are the same as those specified for soft gelatin capsules except for the fact that the use of disks is omitted for tablets. Therefore, larger differences than the ones observed in this study would not be surprising if the product studied was an enteric-coated tablet product. Questions will arise concerning which test conditions are more biorelevant, and thus more suitable to be adopted. Considering the fact that the buffers specified for this test by both pharmacopeias exhibit a buffer capacity much higher than that of intestinal fluid (with this difference being much bigger in the case of $P h$. Eur.) and that the $P h$. Eur. buffer also exhibits a much higher ionic strength (10), the USP buffer might be considered as potentially more biorelevant.

\section{CONCLUSION}

Disintegration testing conditions specified for entericcoated products by the USP and Ph. Eur. can lead to different test results. This shows the importance of harmonizing such tests among the different pharmacopeias. In addition, the development of more physiologically relevant buffer systems for disintegration testing of enteric-coated dosage forms is needed since both the Ph. Eur. and the USP buffers show poor biorelevance. However, until this is achieved, the USP buffer can be used as the one that is potentially more biorelevant.

\section{ACKNOWLEDGMENTS}

We would like to thank Mr. Manfred Penning for his help in obtaining the shellac and the Deutscher Akademischer Austauschdienst (DAAD) for its support. This work was a contribution to the Innovative Medicines Initiative Joint Undertaking (http://www.imi.europa.eu/content/) as a background.

\section{REFERENCES}

1. European Pharmacopoeia, 8th ed.; European Directorate for the Quality of Medicines \& Healthcare, Council of Europe: Strasbourg, France, 2012.

2. The United States Pharmacopeia and National Formulary USP 35-NF 30; The United States Pharmacopeial Convention, Inc.: Rockville, MD, 2012.

3. Wagner, J. G.; Wilkinson, P. K.; Sedman, A. J.; Stoll, R. G. Failure of USP tablet disintegration test to predict performance in man. J. Pharm. Sci. 1973, 62 (5), 859860. DOI: $10.1002 /$ jps.2600620548.

4. Wilding, I. R.; Hardy, J. G.; Sparrow, R. A.; Davis, S. S.; Daly, P. B.; English, J. R. In Vivo Evaluation of Enteric-Coated Naproxen Tablets Using Gamma Scintigraphy. Pharm. Res. 1992, 9 (11), 1436-1441. DOI: 10.1023/A:1015858829187.

5. Cole, E. T.; Scott, R. A.; Connor, A. L.; Wilding, I. R.; Petereit, H.-U.; Schminke, C.; Beckert, T.; Cadé, D. Enteric coated HPMC capsules designed to achieve intestinal targeting. Int. J. Pharm. 2002, 231 (1), 8395. DOI: 10.1016/S0378-5173(01)00871-7.

6. Stippler, E.; Kopp, S.; Dressman, J. B. Comparison of US Pharmacopeia Simulated Intestinal Fluid TS (without pancreatin) and Phosphate Standard Buffer $\mathrm{pH}$ 6.8, TS of the International Pharmacopoeia with Respect to Their Use in In Vitro Dissolution Testing. Dissolution Technol. 2004, 11 (2), 6-10. DOI: 10.14227/DT110204P6.

7. Kararli, T. T.; Kirchhoff, C. F.; Truelove, J. E. Ionic Strength Dependence of Dissolution for Eudragit S-100 Coated Pellets. Pharm. Res. 1995, 12 (11), 1813-1816. DOI: 10.1023/A:1016202814109.

8. Fadda, H. M.; Merchant, H. A.; Arafat, B. T.; Basit, A. W. Physiological bicarbonate buffers: stabilisation and use as dissolution media for modified release systems. Int. J. Pharm. 2009, 382 (1-2), 56-60. DOI: 10.1016/j.ijpharm.2009.08.003.

9. Liu, F.; Merchant, H. A.; Kulkarni, R. P.; Alkademi, M.; Basit, A. W. Evolution of a physiological pH 6.8 bicarbonate buffer system: Application to the dissolution testing of enteric coated products. Eur. J. Pharm. Biopharm. 2011, 78 (1), 151-157. DOI: 10.1016/j.ejpb.2011.01.001.

10. McConnell, E. L.; Fadda, H. M.; Basit, A. W. Gut instincts: Explorations in intestinal physiology and drug delivery. Int. J. Pharm. 2008, 364 (2), 213-226. DOI: 10.1016/j.ijpharm.2008.05.012. 